\title{
Survey on IOT based Smart City Bin
}

\author{
Roshni Bhandari \\ Assistant Professor \\ Computer Department, \\ S.S. Agrawal Institute of \\ Engineering \& Technology Navsari
}

\author{
Singh Nidhi \\ Student \\ B.E. Semester-VII \\ Computer Department \\ S.S. Agrawal Institute of \\ Engineering \& Technology Navsari
}

\author{
Rathod Swapnil \\ Student \\ B.E. Semester-VII \\ Computer Department \\ S.S. Agrawal Institute of \\ Engineering \& Technology Navsari
}

\author{
Desai Dhruvi \\ Student \\ B.E. Sem-VII \\ Computer Department \\ S.S. Agrawal Institute of Engineering \& \\ Technology Navsari
}

\author{
Kotadiya Harsh \\ Student \\ B.E. Sem-VII \\ Computer Department \\ S.S. Agrawal Institute of Engineering \& \\ Technology Navsari
}

\begin{abstract}
The system of interrelated computer devices, mechanical or digital machines, objects, animals or peoples that are provided unique identifiers (UID) are known as INTERNET OF THINGS (IOT). These interrelated entities can transfer data over network which does not require Human to Human or Human to Computer. The IOT definition as been evolved due to convergence of multiple technologies like, The Real Time Analysis, Machine Learning, Commodities Sensors and Embedded systems. The IOT technology is most synonyms with products pretending to the concept of "Smart Home" in the consumer market. The concept of bringing all the general equipments into a single eco-system and transferring data over them is what it basically means. To bring "Waste Management " to an optimal solution we bring concept of IOT based Smart Dustbin because Waste Management is a major issue in today's world. Decreasing the spread of diseases through the waste, less pollution, cleanliness, including waste management, like wise in every manner, constructing a smart dustbin would be beneficial. We can convert Normal Dustbin into Smart and more efficient Dustbin by adding various sensors to the normal dustbin. The overflowing bins around the street, which aren't taken care of, they should be emptied as soon as they get filled up with the waste, is the main issue of waste management the root cause for spreading of various diseases is because of various hazards such as bad odor and ugliness to that place. To maintain the public cleanliness and all such hazardous scenarios and health this work is mounted on a SMART GARBAGE SYSTEM. To develop a smart intelligent garbage alert system for a proper garbage management is the main theme of the work. Adding various sensors like Ultrasonic sensors ( For checking levels of the dustbins and checking the motions of humans as he/she comes nearby to throw the waste.), ARDUINO UNO for transfer of data over an object to the servers/websites/application, various PCB circuits, etc. Various other sensors or equipments can also be used in constructing a Smart Dustbin such as RFID tag, GSM module, Battery, etc. Thus the overall concept of a SMART CITY BIN is to manage waste properly and to avoid the diseases spread by the pollution cause by that waste.
\end{abstract}

\section{Keywords}

Arduino UNO, GSM module, Ultrasonic sensors, Emonitoring, Embedded system, Waste management, Wi-Fi module,

\section{INTRODUCTION}

The identification of Smart cities have been done by promising potential application domain for the Internet Of Things, with the wide range of possible services that can benefit City administration and citizens alike. Smart waste management in a smart city is one service that can be provided .The surroundings environment when they are full for long periods of time can be detracted by public trash can. It can be an expensive operation to send garbage truck to every trash can in the city on the other hand; if cans are empty the journey accomplishes nothing. For minimizing cost of various municipal services such as collecting trash, cities develop rough algorithms; but Internet of Things sensors can improve the services by notify relevant public works officials when particular trash cans are filled.

For the development of the Nation there is a need of "SMART CITY". The increasing depletion of ozone layer is occurring due to rising population. The spreading of diseases in living being is mostly due to pollution increase. The overflowed dustbins on the streets are the main purpose of waste management to look forward for. The efficient management of garbage using various emerging technology like INTERNET OF THINGS is mainly focused by proper maintenance of garbage. Checking the levels of dustbin using ultrasonic sensors is focused in the design of smart dustbin. Checking the level of dustbin on real time bases is focused. For no stealing of fuels a tracking machine is design in garbage truck. A garbage truck is allocated to a specific area that no stealing of fuel is done. As soon as the dustbin gets filled up it sends the notification to the system that the bin is filled, this is how ARDUINO UNO works. Waste from overflowing from the dustbin and spreading pollution is prevented.

We can achieve an efficient way of waste management by the practice of pursuing computing technology like IOT and using Ultrasonic sensors. By using Arduino UNO, we can know the real time status of levels of dustbin. We can take immediate 
action on waste management by knowing the real time status of the bins. We can avail this system at less cost.

\section{LITERATURE SURVEY}

In developed and developing countries the major problem growing is waste management. The waste management should be effectively and efficiently implemented over the cities. The overflowing bins are stinking and unhygienic. The various proposals were put forward while some of them have been already implemented. But it cannot be considered as an effective one. So a survey was done among different proposals and this survey paper includes survey among different methods for Waste Collection System based on IOT.

From paper [1] For proper monitoring and maintenance of garbage an embedded based intelligent alert system is used. At the regular intervals alerts are sent to the concerned individuals for regular cleaning of dustbins. Furthermore the system can be improved by adding the status of cleaning in real time and also additionally measuring of the performance of the team. Thus, in environment maintenance this system comes in handy as an admirable solution. In addition to this it also aids to diminish the need for high human intervention in garbage maintenance of the municipality and pollution monitoring system.

From paper [2] It has collected all the details of Smart Waste Collection System based on IOT and to find out the effective methods which are useful for providing hygiene environment in cities. If the level of garbage bin have crossed the threshold it would be informed to its corresponding authority, if that information is ignored by the corresponding authority then it would be sent to higher authority for the necessary actions. Thus, the hygienic and clean environment can be provided. This paper helps in identifying all possible smart waste collection methods that can be implemented to make city clean.

From paper [3] An embedded based intelligent alert system is devised for the proper monitoring and maintenance of the garbage. This system averts the irregular cleaning of the dustbins by sending alerts to the concerned individual at regular intervals. It further improves the system by additionally endorsing the status of cleaning in real time and measure the performance of the team. Thus this system comes in handy as an admirable solution in environmental maintenance. In addition to this it also aids to diminish the need for high human intervention in garbage maintenance of the municipality and pollution monitoring system.

From paper [4] Primary Collection, Waste Transportation, Storage, Treatment and Disposal are the primary properties and issues for solid waste management The process of recycling with their risk have been studied. The main objective of studying this paper is to rectify all the above risk and issues by using Smart Solutions like Sensors, IOT and Smart Bins. Thus, a clean and a healthy environment free from the solid waste will be developed by this.

From paper [5] In this research, an efficient, cost effective waste management system is introduced. Mechanism to display filled level of dustbins, sending notifications to driver, finding shortest route to reach the destination, receive complaints from the citizen and display the current location of trucks has been provided in this system. It has been estimated that huge amount of money involved in waste collection process for implementing Google Map API to reduce the cost involved in collection process. For avoiding unnecessary slow in Waste Collection Process the driver's application sends its current location to the server so it can display the current location of the Waste Collection Trucks. The main objective of the system is to achieve its implementation.

From paper [6] When the garbage level reaches its maximum this paper works assures the cleaning of dustbins soon. The record is send to higher authority who takes contract, if the dustbin is not cleared in the specific time. The cleanliness in the society is the main of the system. The garbage collection has been made more efficient by the Smart Garbage Management System.

From paper [7] In this paper we will avoid the overflowing of garbage from the container in the residential area which is previously either loaded manually or with the help of loaders and traditional trucks by implementing this project. Besides, manually handling of waste poses a threat to the health of the sanitation workers as the waste is highly contaminated.

From paper [8] In the present world, waste management is the most challenging aspects. It will cause a great damaged to the environment, if the waste is not managed or disposed properly. Thus we have to introduce a new mechanism for the waste management. We have to develop a mechanism in our project for the purpose of waste management. To dispose the garbage in urban areas this mechanism was used. For the purpose of detecting the height of the waste in the dustbin various sensors have been used. A message was send to the truck driver intimating to collect the garbage waste whenever the dustbin was full. For eliminating the present day scenario of leaving the dustbin without cleaning for several days, this system will be helpful. For sending message to the workers who was allotted to that dustbin we are using GSM module. It will create a good communication between the workers and the overloaded dustbins which will help for the maintenance of pollution free environment.

From paper [9] In this paper we can easily dispose the waste present in the garbage bins as early as possible when compared to the previous methods without it affecting it to the peoples and keep these surroundings clean by using this smart garbage monitoring system using RFID over IOT's.

From paper [10] To monitor the level of garbage in the dump, we built an efficient garbage monitoring system. To plan garbage collection trips more efficiently, ultimately reducing overflowing bins and helping have better public sanitation, this data can be further used.

From paper [11] In sorting the waste materials is highly feasible and time efficient by the used of intelligent automation techniques. The knowledge of the machine learning induction algorithms is to enhance system adaptability have been derived by the control system. The preliminary sensor data from acoustic test and light transmission have the potential to differentiate clear and unclear objects. They possess the ability to wisely segregate glass, metals and plastics using emitted sound waves apart from this.

From paper [12] The implementation of smart garbage management system using IR sensors, microcontroller and WI-FI modules in this project work. Soon when the garbage level reaches its maximum, this system assures the cleaning of the dustbin. The record is sent to the higher authority who can take appropriate action against the concern administrator, if the dustbin is not cleaned in specific time. To monitor the fake reports and hence can reduce the corruption in the overall management system is also helpful by this system. The total number of trips of garbage collection vehicle and hence 
reduces the overall expenditure associate with the garbage collection is reduced by this. It ultimately helps to keep cleanliness in the society. Therefore, the smart garbage management system makes the garbage collection more effectively.

\section{CASE STUDY}

From USA, according to the survey we found that different colours of dustbins are kept on the streets for various kinds of waste. Blue, Green \& Black colours are used for Cans \& bottles, Papers \& Waste only repectively. Due to separated bins for various waste, waste management has been made easier. The waste which can be recycled is separated and recycled and useful products can be made out of it. No special technologies are embedded for constant monitoring of garbage level in the bins.

From Russia, according to the survey we found that different colours of bins are made available for different material. Colours used are Blue, Green, Purple \& Red for separating materials like Paper, Plastic, Metal \& Glass respectively. Metal scraps are recycled and used to make antiques and useful furniture. Paper waste is also recycled and converted into useful things. Plastic waste is tried to recycle as much as it can be recycled.

From Srilanka, according to the survey we found that different colours of bins are made available for different material. Colours used are Blue, Brown, Orange, Green, Pink \& Purple for separating materials like Metal, Batteries, Paper, Organic waste, Plastic \& Glass respectively. Metal scraps are recycled and used to make antiques and useful furniture. Paper waste is also recycled and converted into useful things. Plastic waste is tried to recycle as much as it can be recycled.

From China, according to the survey we found that different colours of bins are made available for different material. Colours used are Blue, Black, Green \& Red for separating materials like Metal, Plastic, Organic waste \& Glass respectively.

From India, according the survey separate bins are kept for dry and wet waste. The major issue in india is of overflowing bins on the streets an at the residential areas. Our approach can be a solution to this problem. Using Internet of things and various sensors we can achieve an efficient way of managing the waste.

\subsection{Trading Trash for Health care in Indonesia [13]}

Dr. Gamala Albinsaid saw a connection between general health and the fact that less than half of the 55,000 tons of garbage gets collected in Malang City, Indonesia. Using trash as currency, he created the Garbage Clinical Insurance, which trades garbage for medical services and medicines. The trash cash he collects is converted into money which is then pumped back into his healthcare network.

\subsection{Converting Garbage into usable energy in Sweden[13]}

Sweden is well-known for its progressive environmental strides - the Scandinavian country's waste-to-energy system efficiently provides direct heating to 950,000 Swedish households and electricity to 260,000 homes. Sweden recycles and sorts its trash so effectively that less than $1 \%$ ends up in landfills. Seeing garbage as a commodity, Sweden imports trash from other European countries to fuel its power needs, with $700 \mathrm{~kg}$ (1543 lbs) of rubbish translating into up to $250 \mathrm{~kg}$
(551 lbs) of energy and fuel.

\subsection{An amusement park made from rubbish in Uganda[13]}

Artist and environmentalist Ruganzu Bruno is bringing ecological art to the slums of Kampala. Eco Art Uganda is a collective of artists dedicated to promoting environmental awareness, and the group created an amusement park for children from discarded materials. Recycled swings and lifesize board games made from plastic bottles are just some of the attractions at the Eco Art amusement park. The creative initiative works on many levels - beautifying the community, empowering and educating kids and effectively recycling trash and managing waste.

\subsection{Paving the streets with plastic in India[13]}

Chemistry professor Rajagopalan Vasudevan devised a way to transform common plastic litter into a substitute for bitumen - the main ingredient in asphalt used for road construction. By looking at increased levels of plastic waste due to India's rapid economic development as a blessing in disguise, the eternal optimist views trash as a treasure trove of untapped resources. His method both solves environmental issues and saves money - as the cheaper plastic substitute replaces as much as 15 percent of the more expensive bitumen usually used.

\subsection{A Former landfill turned eco-park in Hongkong[13]}

The Sai Tso Wan landfill used to hold up to 1.6 million tonnes of waste, stacking up to be 65 meters or 213 feet high! After being closed and sealed off with soil in 1981, a multi-purpose playground was created in 2004 powered by wind turbines, solar cells and energy derived from methane generated from the decomposed trash.

\section{OUR APPROACH}

The System works in such a manner that whenever the garbage bin is full it sends the alert message to the municipal officer with the help of microcontroller linked with the web server using IOT. It also provide verification message after the dustbin is cleaned. The level of the garbage is continuously check by the ultrasonic sensors. Whenever the level of threshold is reached the ultrasonic senor sends the indication to the Arduino Uno through the GSM. SMS will be send to the control room that "Please collect the garbage of specific area ". The collector will collect the garbage and the verification message is send. The Garbage truck is tracked with the help of GPS tracking system, so that fuel is comsumed less.

\section{DIFFERENT METHODOLOGIES}

There are different types of sensors and technologies that can be embedded and involved in this approach to make the process much easier, using Internet of Things makes an interaction with any object and internet, we shall see some of the sensors equipments and modules that can be used in this approach

\subsection{Embedded system}

The system embedded in this technology is ultrasonic sensors. Ultrasonic sensors are embedded at both places i.e. inside the bin and outside the bin. Inside the bin to know that the waste level in the bin is below the alerting mark and outside the bin to check any movements outside the bin so that it can open 
automatically detecting a person's movement. The lid automatically opens on sensing the movement outside the bin using the ultrasonic sensor embedded outside the dustbin.

\subsection{E-monitoring System}

With the increasing in pollution due to overflowing dustbins these days, proper waste management have became a necessity for a good and health life of the society. Municipal waste left over has been an emerging problem these days. Using efficient and better technologies to overcome those problems could be a good solution. In traditional approach the garbage truck comes near the dustbin, the worker checks if it's filled or not and then unloads it or keep it as it is if it's empty. We proposing a new technique of waste management by Internet of things (IOT), in general IOT is nothing but simply flowing or accessing of data through various objects in real time. The technology behind this approach is using Ultrasonic sensors for checking the levels of dustbins, how much it's loaded or what percentage of dustbin is filled with waste. ARDUINO UNO sends the real time data to the app, it sends the alerts to the app if the dustbin is about to get full.

The e-monitoring system has two parts:

- $\quad$ Embedded system

- Web-based software system interface

\subsection{Web based System Software}

This comprises of a GPRS module connected with a central server which basically has all the real time information of the system, which consists of all the information sent by the sensors to the controllers.

The central theme of the proposed system is to monitor the municipal waste in order to manage it properly. By using ultrasonic sensors the system can be made in a cheap cost. Not only monitoring the real time results but also checking activities of their team and analyzing that they can be more productive.

\subsection{AURDINO UNO}

The Arduino Uno is a microcontroller board grounded on the ATmega328 (datasheet). It comprises of 14 digital input/output pins (out of which 6 can be utilized as PWM outputs), 6 analog inputs, a $13 \mathrm{MHz}$ ceramic resonator, a facilitation for USB connectivity, a power jack, an ICSP header, and a reset button. Its designs comprises of assistances that supports the microcontroller in every possible way. In order to get to work with it one has to simply connect it to a computer with a USB cable or power it with an AC-to-DC adapter or battery.

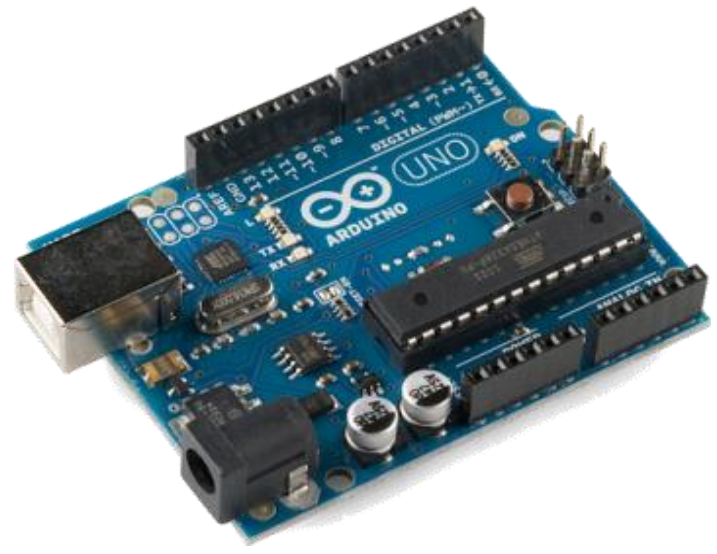

Fig 1 : ARDUINO UNO
It is accessible in two different versions namely Arduino Uno and Genuine Uno which could be visualized in Figure. The variations are observed with reference to the region. The Uno is unique from all its former boards in the way that it does not make use of the FTDI USB-to-serial driver chip.

The word "Uno" refers to one in Italian and it is named so to mark the forthcoming release of Arduino 1.0. The Uno and version 1.0 are the reference versions of Arduino in the forward journey. The Uno is the latest in a series of USB Arduino boards, and the reference model for the Arduino platform.

\subsection{ULTRASONIC SENSOR HC - SR04}

Ultrasonic ranging module HC - SR04 offers a $2 \mathrm{~cm}-400 \mathrm{~cm}$ non-contact measurement function, the ranging accuracy could reach up to $3 \mathrm{~mm}$. The building modules includes ultrasonic transmitters, receiver and control circuit.

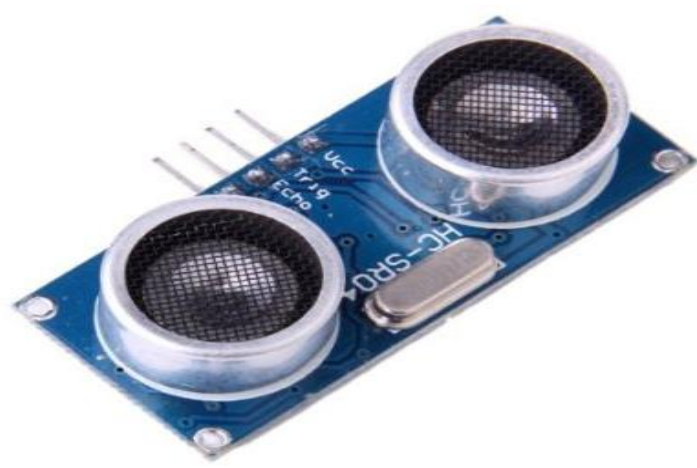

Fig 2 : Ultrasonic sensor HC SR04

The basic principle:

(1) Making use of IO trigger for at least 10us high level signal,

(2) The Unit inevitably sends eight $40 \mathrm{kHz}$ and detects whether there is any pulse signal back.

(3) If any of a signal is received back in a high level, time of high output IO duration is the time from sending ultrasonic signal and receiving it back. Test distance $=($ high level time $\times$ velocity of sound $(340 \mathrm{M} / \mathrm{S}) / 2$.

\subsection{GSM Module}

GSM modem as a supply voltage range of about $3.8 \mathrm{~V}-4.1 \mathrm{~V}$. It is a low power consumption device which is $1.5 \mathrm{~mA}$.It also has operating Temperature from $-40^{\circ} \mathrm{C}$ to $85^{\circ} \mathrm{C}$. To get easily connected to various devices, it has communication interfaces like serial port, RS232 USB. The power supply circuit has also been providing on GSM module.

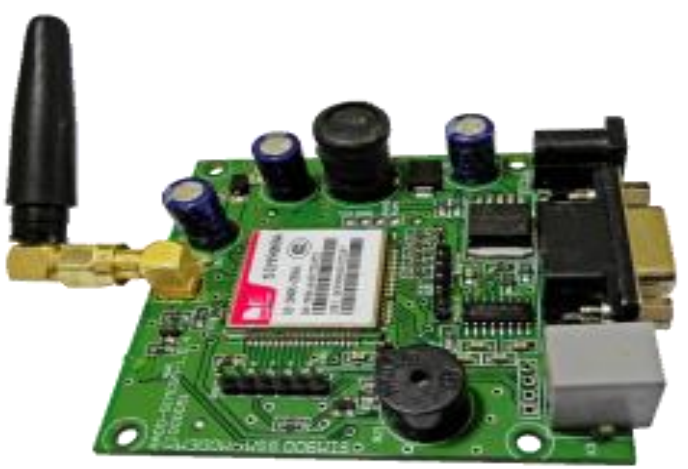

Fig 3 : GSM module 
The switch will be connected digital pin 8 of Arduino as an Input. Whenever we press the switch the Arduino will communicate with GSM module by Using AT commands and send "MESSAGE" to the program mobile number. AT + CMGS at command is used to send SMS.

\section{CONCLUSION}

From the above paper, the proper disposal of waste and its management has been studied. The risks due to waste pollution due to overflowing of the dustbins has been observed and rectified. It has been known that by using Internet of things (IOT) for a proper waste management, we can have a proper and pollution free city and thereby making the nation neat and clean. Using of smart sensors like Ultrasonic sensors, embedding them into the smart bin we can have an efficient way of waste management.

\section{REFERENCES}

[1] Jenifer Prathana, IOT based smart garbage alert system using Arduino UNO, IEEE, November 2013

[2] Shashank Shukla, Smart waste collection System based on IOT, IJCA Vol. 132, and March 2017

[3] G. Anushri, Garbage Monitoring System Using Arduino, IJIRS Vol 8, April 2018

[4] Resmi Rajendra, A Critical Review on Smart City Platform Development for Waste management, IJSART Vol 4, November 2018
[5] A.L.Hanees, IOT Based Waste collection monitoring system using smart phones, International Symposium2018 SEUSL.

[6] R. Manikandan, An Analysis of Garbage Mechanism for Smart cities, IRJET Vol 6, Jan 2019

[7] Prof. Reena Sudhakarrao Satpute, Smart Garbage Monitoring System using IOT based, IJARIIE Vol 4, Feb 2018

[8] S. Jaya Kumar, Ultrasonic Assisted Smart Garbage Monitoring System, JNCET Vol 8, April 2018

[9] M. Narayana, Smart Garbage Monitoring System Using Sensors with RFID over Internet Of Things, JARDC, Vol 9, June 2017

[10] Md. Aasim Anwar, IOT based Garbage Monitoring using Arduino, RCC Institute of IT, May 2018

[11] Praveen Kumar Gupta, The Use of modern technology in smart waste management system and recycling: artificial intelligence and machine learning, Research gate, April 2019

[12] S.S. Navghane, IOT based smart garbage and waste collection bin, IJARECE Vol 5, May 2013

[13] Countries With a Creative Approach to Trash Disposal, 